\title{
Relationship Between Invasive Brown Marmorated Stink Bug (Halyomorpha halys) and Fumonisin Contamination of Field Corn in the Mid-Atlantic U.S.
}

\author{
Joseph Opoku ${ }^{1}$, Nathan M. Kleczewski ${ }^{2}$, Kelly A. Hamby ${ }^{3}$, D. Ames Herbert ${ }^{1}$, Sean Malone ${ }^{1}$, and Hillary L. Mehl ${ }^{1, \dagger}$ \\ ${ }^{1}$ Virginia Tech Tidewater Agricultural Research and Extension Center, Suffolk, VA 23437; ${ }^{2}$ Department of Crop Sciences, Uni- \\ versity of Illinois, Urbana, IL 61801; and ${ }^{3}$ Department of Entomology, University of Maryland, College Park, MD 20742
}

\begin{abstract}
Brown marmorated stink bug (Halyomorpha halys Stål) is an invasive agricultural pest that causes severe damage to many crops. To determine potential associations between $H$. halys feeding damage, Fusarium infection, and mycotoxin contamination in field corn, a field survey was conducted in eight counties in Virginia. Results indicated an association between $H$. halys feeding damage and fumonisin contamination. Subsequent field experiments in Delaware, Maryland, and Virginia examined the ability of $H$. halys to increase Fusarium verticillioides (Sacc.) Nirenberg infection and fumonisin concentrations in corn. At the milk stage, $H$. halys (0 or 4 adults) and Fusarium (with or without F. verticillioides

inoculum) treatments were applied to bagged ears in a two by two factorial randomized complete block design with 12 replicates. $H$. halys treatments increased levels of feeding damage $(P<0.0001)$ and Fusarium infection $(P=0.0380)$. Interaction between $H$. halys and Fusarium treatments influenced severity of infection $(P=0.0018)$ and fumonisin concentrations $(P=0.0360)$. Results suggest $H$. halys has the ability to increase both Fusarium infection and fumonisin concentrations in field corn. Further studies are needed to understand mechanisms by which $H$. halys increases fumonisin and to develop management strategies to mitigate impacts of $H$. halys on field corn in the region.
\end{abstract}

The brown marmorated stink bug, Halyomorpha halys Stål (H. halys), is an invasive insect pest that originated from eastern Asia. $H$. halys was first reported in the United States from Allentown, PA, in the late 1990s (Hoebeke and Carter 2003), and the insect quickly spread throughout Pennsylvania and into New Jersey, northern Delaware, Maryland, and Virginia (Hamilton 2009). Since then, H. halys has become a key pest in annual and perennial crops in the midAtlantic region and has also appeared in the Pacific Northwest (Lee 2015). H. halys is polyphagous and attacks over 300 economically important plant hosts, including field corn (Zea mays L.) (Leskey et al. 2012a,b; Nielsen and Hamilton 2009; Zhu et al. 2012). In midAtlantic field corn, peak $H$. halys pressure occurs during blister, milk, and dough stages (R2-R4) (Venugopal et al. 2015), when H. halys feed on developing kernels and reduce kernel quality by discoloring and shrinking kernels (Cissel et al. 2015; Hedstrom et al. 2014; Rice et al. 2014; Venugopal et al. 2014). This feeding damage occurs primarily on field edges, where up to $8 \%$ of kernels are damaged (Venugopal et al. 2014). Economic thresholds have not been developed for corn, and there have not been reports of stink bug feeding alone impacting marketable grain quality. However, the economic significance of $H$. halys damage could potentially be more severe if $H$. halys feeding increases incidence of fungal infections and mycotoxin contamination.

Insect feeding injury may facilitate ear invasion by opportunistic pathogens and may also induce stress that predisposes ears to diseases such as Fusarium ear rot (Avantaggiato et al. 2002; Munkvold 2003; Payne 1999; Smeltzer 1959). Ear rot, caused by Fusarium spp. including $F$. verticillioides (Sacc.) Nirenberg, F . proliferatum (Matsush.) Nirenberg, and $F$. graminearum Schwabe, is common in the mid-Atlantic region and contributes to poor quality and mycotoxin contamination of corn grain (Stumpf et al. 2013). The FDA has advisory guidance for the Fusarium toxins fumonisin (mainly by $F$. verticillioides and $F$. proliferatum, $<2 \mathrm{ppm}$ to $100 \mathrm{ppm}$, depending on the

${ }^{\dagger}$ Corresponding author: Hillary L. Mehl; hlmehl@vt.edu

Funding: This work was funded in part by the Delmarva Land Grant Institution Collaborative Research Seed Funding Program.

Accepted for publication 16 November 2018.

(C) 2019 The American Phytopathological Society intended use) and deoxynivalenol (mainly by $F$. graminearum, 1 ppm to $5 \mathrm{ppm}$ ) in food and feed. There are no advisory guidelines for zearalenone, another toxin produced by certain Fusarium spp., but it is frequently associated with the presence of other mycotoxins and causes reproductive problems in livestock (El-Nezami et al. 2002; Kurtz and Mirocha 1978). The only mycotoxin for which the FDA has established regulatory levels in corn is aflatoxin (produced by Aspergillus flavus Link); action levels in corn range from $20 \mathrm{ppb}$ (human consumption) to $300 \mathrm{ppb}$ (feed for mature beef cattle). A. flavus infection and associated aflatoxin contamination, which are favored by hot, dry conditions, are less common in the mid-Atlantic but can be a significant problem in certain years ( $\mathrm{H}$. Mehl, unpublished data). Corn contaminated with mycotoxins near or above regulatory or advisory levels can result in poor prices or rejection at grain elevators, resulting in an economic loss for growers (Mitchell et al. 2016; Vardon et al. 2003).

Although the association of insects and mycotoxin contamination has been documented for a wide range of insect orders and species (Dowd 1998), the extent to which $H$. halys contributes to fungal infection and mycotoxin contamination has not been adequately studied. Previous research in the southeastern United States demonstrated an association between native brown stink bug (Euschistus servus) feeding and preharvest aflatoxin contamination in corn (Ni et al. 2010, 2011). However, in the mid-Atlantic, native stink bug populations have not typically been at high enough numbers to cause significant damage. Mass $H$. halys invasion of corn fields in the region may cause greater levels of feeding injury and potentially lead to increases in mycotoxin contamination.

Prior and current research on $H$. halys has focused on understanding the biology of the insect, the damage caused by $H$. halys to a variety of crops, and the most effective strategies for mitigating damage and crop losses from this invasive pest (Cissel et al. 2015; Hoebeke and Carter 2003; Leskey et al. 2012a,b; Rice et al. 2014; Venugopal et al. 2014). However, the extent to which $H$. halys impacts mycotoxin contamination levels in field corn has not been determined. Thus, the objectives of this research in field corn were to: 1) determine if there is a relationship between $H$. halys infestation, feeding injury, and the presence of mycotoxin contamination, and 2) examine the ability of $H$. halys to increase Fusarium infection and fumonisin contamination.

\section{Materials and Methods}

Field survey. In July 2013, when the corn crop was at or near the milk stage, high numbers of $H$. halys (10 or more per ear) were 
observed along the edges of corn fields throughout central Virginia. In mid-September just prior to harvest, corn ears were collected from fields where $H$. halys infestations had been documented. A total of eight fields were sampled in Albemarle, Powhatan, Orange, Madison, Culpeper, Frederick, King George, and Spotsylvania counties. At each field, two to four corn ears were collected from three different locations along the field edge where high levels of $H$. halys feeding damage was observed earlier in the growing season. Since $H$. halys infestations and signs of feeding damage were confined primarily to field edges, a second set of two to four ears were collected 12 to 20 rows into the field (straight in from each edge location) so damaged and undamaged ears could be compared. Ears were handshelled with a metal corn sheller (Decker Manufacturing, Keokuk, IA) and kernels were dried in paper bags at $45^{\circ} \mathrm{C}$ for $72 \mathrm{~h}$.

Assessment of kernel damage. Shelled kernels were thoroughly mixed by hand, and damage was quantified from a $70 \mathrm{~g}$ subsample. Kernels were visually inspected to determine the percentage of kernels with evidence of stink bug feeding damage, which includes a puncture scar surrounded by a discolored cloudy marking, and sunken, shrunk, and collapsed kernels as described previously (Cissel et al. 2015; Hamilton and Shearer 2003; Venugopal et al. 2014).

Fungal infection. Frequency of fungal infection was determined from 20 randomly selected kernels from each sample. Kernels were surface disinfested with $10 \%$ commercial bleach for $2 \mathrm{~min}$, air dried, and plated (5/plate) on 1/4 strength potato dextrose agar (PDA, 9.75 $\mathrm{g} /$ liter) (Fisher Scientific, Ottawa, Canada) amended with $100 \mathrm{mg} /$ liter chloramphenicol and $100 \mathrm{mg} /$ liter chlortetracycline. Plates were incubated at room temperature $\left(25^{\circ} \mathrm{C}\right)$ for 5 to 7 days. The number of kernels with fungal growth was quantified, and fungi were identified to genus and in some cases species based on spore and culture morphology (Barnett and Hunter 1998; Leslie and Summerell 2006).

Single-spore purification of isolates. Fusarium isolates were grown on full strength PDA (39 g/liter) for 5 days. A piece of the growing Fusarium culture was picked with a sterile toothpick and gently streaked across the surface of $2 \%$ water agar. Following incubation $\left(25^{\circ} \mathrm{C}, 16 \mathrm{~h}\right)$, water agar plates were inspected under a dissecting microscope $(10 \times)$ to identify germinating conidia. A sterile toothpick was used to cut out and transfer a single germinating conidium to full strength PDA. Single-spore isolates were grown at $25^{\circ} \mathrm{C}$ for 4 to 7 days to obtain a pure culture.

Filter paper archival cultures. Sterilized Whatman \#1 qualitative filter papers of $7 \mathrm{~cm}$ diameter were cut into two and each half placed on full strength PDA approximately $3 \mathrm{~mm}$ apart. Single-spore purified Fusarium cultures were then transferred to the center of the plate and allowed to grow at $25^{\circ} \mathrm{C}$ for 5 days. Colonized filter paper was aseptically transferred to sterile empty Petri dishes and oven dried at $45^{\circ} \mathrm{C}$ for $72 \mathrm{~h}$. Sterilized scissors were used to cut one of the dried filter papers into pieces (about $5 \times 5 \mathrm{~mm}$ ) and placed in a sterile $7.62 \times 11.43 \mathrm{~cm}$ envelope (Uline, Atlanta, GA) and kept at $4{ }^{\circ} \mathrm{C}$. A piece of the cut filter paper was used to regenerate a copy of the isolate when needed. The other half was kept at $-20^{\circ} \mathrm{C}$ for long-term storage.

Molecular identification of $\boldsymbol{F}$ usarium spp. Seven representative isolates with different culture and spore morphologies were sequenced to confirm Fusarium species identification. Fungal DNA was isolated using the FastDNA SPIN kit (MP Biomedicals, Solon, $\mathrm{OH}$ ). Samples were homogenized in a Mini-BeadBeater 24 (Bartlesville, $\mathrm{OH}$ ) for $40 \mathrm{~s}$ at a speed of 3,000 rpm. Subsequent steps were performed according to the manufacturer's protocol. DNA was eluted with a final volume of $200 \mu \mathrm{l}$ of ddH20. The translation elongation factor (TEF1- $\alpha$ ) gene was amplified using HotStart PCR PreMix (Bioneer, Inc., Alameda, CA) with $0.2 \mu \mathrm{M}$ of the forward primer and reverse primers (EF1 and EF2, O'Donnell et al. 1998) and $10 \mathrm{ng}$ template DNA in a total volume of $20 \mu \mathrm{l}$. PCR was performed using a Bio-Rad T 100 thermocycler with the following conditions: an initial denaturing step at $94^{\circ} \mathrm{C}$ for $5 \mathrm{~min}$ followed by 35 cycles of $94^{\circ} \mathrm{C}$ for $40 \mathrm{~s}, 53^{\circ} \mathrm{C}$ for $1 \mathrm{~min}$, and $72^{\circ} \mathrm{C}$ for $1 \mathrm{~min}$; followed by a final extension at $72^{\circ} \mathrm{C}$ for $5 \mathrm{~min}$. The amplicons were run on a $1.5 \%$ agarose gel with $1 \times$ Tris/Borate/EDTA (TBE) as buffer and gel red as the DNA intercalating fluorescent dye. Amplicons were visualized under UV light by using molecular imager Gel Doc XR system (Bio-Rad Laboratories, Hercules, CA) to confirm the amplicon size of $\sim 700 \mathrm{bp}$. Five microliters of the amplicon was purified using ExoSap-IT kit (Affymetrix Inc., Santa Clara, CA) following the manufacturer's instructions. The purified amplicons were submitted to the Virginia Biotechnology Institute (VBI), Virginia Tech, Blacksburg, VA, for sequencing in both directions. A consensus sequence was generated by aligning the forward and reverse sequences using Geneious software version 8.1, and a BLAST search of the National Center for Biotechnology Information (NCBI) databases was performed to determine the species. Sequences were deposited in GenBank (accession nos. MH496628-MH496634).

Mycotoxin extraction and quantification. Neogen's Reveal Q+ kits (Neogen Corporation, Lansing, MI) were used to quantify fumonisin, deoxynivalenol, zearalenone, and aflatoxin from each corn sample. Kernels were pulverized using a Bunn-O-matic gourmet coffee grinder (Bunn-O-matic Corporation, Springfield, IL). For extraction of fumonisin, zearalenone, and aflatoxin, $50 \mathrm{ml}$ of $65 \%$ ethanol was added to $10 \mathrm{~g}$ of each sample and the mixture was vigorously shaken in a floor model shaking incubator (VWR Corporate, Suwanee, GA) for $3 \mathrm{~min}$. For extraction of deoxynivalenol, $100 \mathrm{ml}$ distilled water was added to $10 \mathrm{~g}$ of sample and the sample was mixed as described above. Toxins were then extracted and quantified according to the manufacturer's protocol using Reveal Q+ test strips and the Accuscan Pro instrument. The ranges of detection were 0.3 to $6 \mathrm{ppm}$ for fumonisin, 50 to $1,200 \mathrm{ppb}$ for zearalenone, 2 to $150 \mathrm{ppb}$ for aflatoxin, and 0.3 to $6 \mathrm{ppm}$ for deoxynivalenol. If samples exceeded the upper limit of detection, they were diluted 1:10 in the sample diluent provided with the kit and requantified using a new test strip.

Assessment of $\boldsymbol{H}$. halys impacts on fungal infection and mycotoxin contamination. Based on the 2013 field survey, it was determined that $H$. halys infestations were most frequently associated with $F$. verticillioides ear rot and fumonisin contamination. An experiment including $H$. halys and $F$. verticillioides treatments was conducted and replicated three times to demonstrate reproducibility. Experiments were replicated across three field locations (Delaware, Maryland, and Virginia) in 2015. Since this was a "proof of concept" study to determine if $H$. halys is able to increase fungal infection and mycotoxins rather than a study to look at the magnitude of the effect across locations/environments, it was conducted in a single year with the different locations as independent, replicated experiments. Bt corn hybrid N68B-3111 treated with Cruiser Maxx (Syngenta U.S., active ingredients: thiamethoxam insecticide, mefenoxam fungicide, and fludioxinil fungicide) was planted at a seeding rate of approximately 30,000 seeds per acre and managed according to each location's cooperative extension service guidelines. For the experiment, four rows spaced 30 inches apart were utilized for all locations. Records of temperature, rainfall, and relative humidity for Virginia, Maryland, and Delaware were obtained from the PeanutCotton InfoNet, Central Maryland Research and Education Center (CMREC) Beltsville Facility, and Delaware Environmental Observing System (DEOS), respectively. Descriptions of experimental sites and dates of planting, application of treatments, and harvest are shown in Table 1.

Source of $\boldsymbol{H}$. halys colonies. $H$. halys used for the experiment in the Virginia location were collected from forest edges in Blacksburg, VA, just prior to initiation of the experiment. $H$. halys cultures for the Delaware location were obtained from Phillip Alampi, Beneficial Insect Rearing Laboratory, New Jersey Department of Agriculture, Division of Plant Industry, Trenton, NJ. H. halys for the Maryland location were collected from soybean fields in Clarksville, MD, and held in the laboratory under typical colony conditions (as described in Taylor et al. 2017) until field deployment 10 days later.

Fungal inoculum. $F$. verticillioides isolated from fumonisincontaminated corn collected from Spotsylvania County, Virginia, during the 2013 field survey was used for inoculum in all three experiments. $F$. verticillioides suspension was made by growing pure cultures on full strength PDA for 5 days at $25^{\circ} \mathrm{C}$ and scraping the culture (mostly conidia) into $500 \mathrm{ml}$ of sterile, purified water. The conidial 
suspension was then vigorously shaken to mix. The concentration of the conidial suspension was determined by using a hemocytometer and a final concentration was adjusted to $1 \times 10^{6}$ conidia $/ \mathrm{ml}$.

Experimental design and treatment application. The experiment consisted of a factorial arrangement of treatments in a randomized complete block design. The main factors were $H$. halys treatments (zero or four adult $H$. halys per ear) and Fusarium treatments (water or conidial suspension of $F$. verticillioides). Thus, the four treatment group combinations were untreated control, $H$. halys only, $F$. verticillioides only, and $H$. halys plus $F$. verticillioides. At tasseling, 12 ears of uniform size were selected from each of the four rows for application of treatments. Selected ears were covered with mesh bags ( 28 by $29 \mathrm{~cm}, 3.8$-liter mesh elastic top bag strainer, Trimaco, Morrisville, NC) to prevent insect feeding. At the R3 (milk) stage, treatments were randomly applied to the selected individual ears of plants in four rows of corn. Four milliliters (10 sprays) of $F$. verticillioides conidial suspension or water were applied to the surface of the developing ear using a handheld spray bottle. For $H$. halys infestation treatments, four adult $H$. halys were applied to bagged ears. Each treatment was replicated three times in each row resulting in 12 experimental units (ears) per row and 48 experimental units per experiment. After 7 days, $H$. halys were removed but ears remained covered with mesh bags until harvest. At maturity, the corn ears were hand harvested and dried at $45^{\circ} \mathrm{C}$ for $72 \mathrm{~h}$ to reduce the moisture level to approximately $15 \%$. Signs of $H$. halys feeding damage, kernel infection, and fumonisin concentrations were determined for each sample as described above.

Quantification of $\boldsymbol{F}$. verticillioides DNA (qPCR). To estimate the total quantity of $F$. verticillioides colonizing the kernels, real-time quantitative PCR (qPCR) was conducted using previously developed F. verticillioides-specific primers (Mulè et al. 2004). Two hundred milligrams of ground corn was weighed into a lysing matrix A tube, and DNA was isolated following FastDNA SPIN kit (MP Biomedicals, Solon, $\mathrm{OH}$ ) protocol with the modifications indicated above. Prior to running the samples, a SYBR green assay was validated and optimized to ensure accuracy and reproducibility of the quantification of samples. The reaction mixture for the qPCR was run under temperature gradient from 55 to $65^{\circ} \mathrm{C}$ to determine the optimum annealing temperature. The melt curve generated from the qPCR reaction analysis was evaluated to confirm primer specificity and fidelity. Real-time qPCR reaction mixtures included $5 \mu$ l of SsoAdvanced universal SYBR Green Supermix (Bio-Rad Laboratories, Hercules, CA), $3 \mu$ l of DNA template, and $1 \mu l$ each of the $250 \mathrm{nM}$ forward and reverse $F$. verticillioides specific primers (Mulè et al. 2004) in a total volume of $10 \mu$ l. Each sample was analyzed in triplicate. Each run included a standard curve in triplicate that consisted of 10 -fold dilutions of $F$. verticillioides DNA from 6 to $6 \times 10^{-5} \mathrm{ng}$ per reaction. Reactions were performed on a Bio-Rad Laboratories CFX Connect Real-Time PCR Detection System (Bio-Rad Laboratories, Hercules, CA) with an initial denaturation of $98^{\circ} \mathrm{C}$ for 3 min followed by 40 cycles of $98^{\circ} \mathrm{C}$ for $15 \mathrm{~s}, 62^{\circ} \mathrm{C}$ for $2 \mathrm{~min}$, and a plate read after each cycle. A melt curve was run from 65 to $95^{\circ} \mathrm{C}$ with $0.5^{\circ} \mathrm{C}$ increments for $5 \mathrm{~s}$ and followed by a plate read. Based on the standard curve, quantities of $F$. verticillioides DNA in each sample were calculated by the Bio-Rad CFX Connect Real-Time PCR Detection System software.

Statistical analyses. In order to meet the assumptions of normality and homogeneity of variance for an analysis of variance, percentage data and concentration data were arcsine and log transformed, respectively. For the field survey, field location (county) and sample location (edge versus interior of field) were included as variables in the analysis. The effects of field location and sample location on percent kernel infection and mycotoxin concentrations were assessed with an analysis of variance.

For the analysis of the field experiment, individual ears served as the experimental units. The experiment was analyzed as a full factorial with $H$. halys treatment, Fusarium treatment, and experiment (location) as dependent variables in the analysis of variance. Comparison of least square means was conducted using the LSMeans Tukey's HSD. Values were considered significantly different at $P<0.05$ and JMP Pro version 13.0.0 (SAS Institute Inc., Cary, NC) was used for the analysis of all data in both experiments. Presented values are back-transformed means.

\section{Results}

Field survey. Signs of stink bug feeding injury ranged from 0.6 to $40.1 \%$ of the kernels on ears collected from eight corn fields that were infested with $H$. halys in 2013. Ears collected from field edges had higher levels of feeding injury compared with ears collected from field interiors ( 22.5 versus $2.0 \%$ of kernels, $P<0.0001)$. The fungal genus most frequently isolated from kernels was Fusarium (Table 2). Based on morphology, most of the isolates resembled $F$. verticillioides, a causal agent of fumonisin contamination in corn. Based on a BLAST search of seven sequenced isolates representing the different Fusarium morphotypes, four were confirmed

Table 2. Variation in frequencies of fungal infection and concentrations of mycotoxins in kernels collected from field edges and interiors at eight Virginia corn fields infested with Halyomorpha halys in $2013^{\mathrm{x}}$

\begin{tabular}{lcccccc}
\hline & \multicolumn{2}{c}{ Mean } & & \multicolumn{3}{c}{$\boldsymbol{P}$-valuez } \\
\cline { 2 - 3 } \cline { 5 - 6 } Variabley & $\begin{array}{c}\text { Field } \\
\text { edge }\end{array}$ & $\begin{array}{c}\text { Field } \\
\text { interior }\end{array}$ & & Location & $\begin{array}{c}\text { Edge versus } \\
\text { interior }\end{array}$ & Interaction \\
\hline Fusarium, \% & 31 & 18 & & 0.06 & 0.02 & 0.98 \\
A. flavus, \% & 0.4 & 0 & & 0.28 & 0.07 & 0.28 \\
A. niger, \% & 3 & 2 & & 0.49 & 0.72 & 0.21 \\
Penicillium, \% & 7 & 9 & & 0.16 & 0.43 & 0.50 \\
Other fungi, \% & 4 & 5 & & 0.50 & 0.86 & 0.68 \\
Total infection, \% & 44 & 32 & & 0.04 & 0.08 & 0.81 \\
Fumonisin, ppm & 13.3 & 1.9 & & 0.0005 & $<0.0001$ & 0.28 \\
Zearalenone, ppb & 99 & 81 & $<0.0001$ & 0.06 & 0.11 \\
Deoxynivalenol, & 0.4 & 0.5 & 0.0012 & 0.21 & 0.90 \\
ppm & & & & & 0.47 \\
Aflatoxin, ppb & 0.9 & 0.9 & 0.0002 & 0.25 &
\end{tabular}

${ }^{\mathrm{x}}$ Fields were selected where high levels of $H$. halys feeding were observed earlier in the season. For each field, two to four corn ears were collected from three sampling locations each along the field edge and interior (12 to 20 rows into the field from each edge location).

y Both fungal infection and mycotoxin concentrations were assessed for each sample. Infection with fungal pathogens was assessed by plating 20 randomly selected kernels on 1/4 strength potato dextrose agar. After 1 week, the number of kernels with fungal growth were counted and fungal species were identified based on morphological characteristics. Mycotoxin concentrations were quantified from ground kernels with Neogen Reveal Q+ kits.

${ }^{\mathrm{z}}$ For each measured variable (\% infection or mycotoxin concentrations), the effects of field location and location within the field (edge versus interior) were assessed with an analysis of variance.

Table 1. Summary of experimental sites, cropping history, and dates of field corn planting, treatment application, and harvest in Delaware, Maryland, and Virginia, where experiments were conducted to assess the impacts of Halyomorpha halys feeding on Fusarium verticilliodes infection and fumonisin contamination in 2015

\begin{tabular}{|c|c|c|c|c|c|}
\hline Experiment (location) & Experimental site & Previous crop & Planting date & Treatment date ${ }^{\mathrm{z}}$ & Harvest date \\
\hline$\overline{\mathrm{DE}}$ & Newark Agriculture Research Station & Corn & 1 Jun & 17 Aug & $21 \mathrm{Sep}$ \\
\hline MD & $\begin{array}{l}\text { Central Maryland Research and Education } \\
\text { Center (Beltsville) }\end{array}$ & Vegetables & 29 Jun & $11 \mathrm{Sep}$ & 26 Oct \\
\hline VA & $\begin{array}{l}\text { Tidewater Agricultural Research and } \\
\text { Extension Center (Suffolk) }\end{array}$ & Cotton & 11 Jun & $3 \mathrm{Sep}$ & 7 Oct \\
\hline
\end{tabular}

${ }^{\mathrm{z}} H$. halys and F. verticillioides treatments were applied at the milk (R3) stage of kernel development in the crop. 
as $F$. verticillioides. The other three isolates were $F$. proliferatum (two isolates) and $F$. incarnatum (Roberge) Sacc. (one isolate). Other isolated fungi included A. flavus, A. niger Tiegh., and Penicillium spp. A greater proportion of the kernels collected from field edges were infected with Fusarium compared with kernels collected from field interiors $(P=0.02)$. The proportion of corn kernels infected with the other fungi did not differ between the edge and middle of fields (Table 2).

Fumonisin, zearalenone, deoxynivalenol, and aflatoxin were all detected from corn kernels, but only fumonisin exceeded FDA advisory levels (Table 2). Concentrations of all four mycotoxins varied among locations, but fumonisin was consistently higher in corn collected from field edges than in corn collected from field interiors. Fumonisin concentrations were positively correlated with the proportion of kernels infected with Fusarium spp. $\left(r^{2}=0.33, P<0.0001\right)$ and the proportion of kernels with signs of stink bug feeding injury $\left(r^{2}=0.26, P=0.0004\right)$. Subsamples of injured kernels separated from uninjured kernels were also analyzed and in some cases had over 100 ppm fumonisin (data not shown).

Assessment of $\boldsymbol{H}$. halys impacts on fungal infection and mycotoxin contamination. Maximum and minimum temperatures between planting and the application of treatments at the milk (R3) stage of the corn crop were similar among experimental locations (Table 3). However, rainfall varied among experiments with the MD location receiving less than half the rainfall recorded at DE and VA locations. Between application of treatments (R3) and harvest, temperatures were cooler at the MD location compared with DE and VA locations, and the DE location received considerably less rainfall compared with the other two locations. Overall, the warm temperatures and consistent rainfall at the VA location were more favorable for fungal infection compared with the DE and MD locations.

Following harvest, signs of $H$. halys feeding injury (discolored, sunken, collapsed, and aborted kernels) ranged from $0 \%$ of the kernels from the untreated ears to a maximum of $27 \%$ from the $H$. halys treated ears. The percentage of kernels on harvested ears with signs of $H$. halys feeding injury varied among $H$. halys treatments $(P<$ $0.0001)$ and experiments $(P<0.0001)$ but did not vary with Fusarium inoculation treatment $(P=0.98)$. There were no treatment interactions or treatment by experiment interactions $(P>0.05)$, so main effects were analyzed. Percent injured kernels was higher in the VA experiment compared with the experiments at the other two locations, but overall, treatments that included $H$. halys infestation had significantly more injury compared with treatments without $H$. halys (Table 4).

Frequency of Fusarium infection varied among $H$. halys treatment $(P=0.038)$, Fusarium treatment $(P=0.019)$, and experiments $(P<$ $0.0001)$. Over $40 \%$ of the kernels at the VA location were infected with Fusarium whereas only $11.7 \%$ of kernels were infected at the MD location. This was likely due to warm, wet temperatures in VA and cool temperatures in MD following application of the fungal inoculum (Table 3). However, despite variation in overall levels of

Table 3. Mean daily maximum and minimum temperature and total rainfall between planting and application of Halyomorpha halys and Fusarium verticillioides treatments to corn ears and between treatment application and harvest at three locations where experiments were conducted to assess the impacts of stink bug feeding on fungal infection and fumonisin contamination $^{\mathrm{y}}$

\begin{tabular}{|c|c|c|c|c|c|c|}
\hline \multirow{3}{*}{$\begin{array}{l}\text { Experiment } \\
\text { (location) }\end{array}$} & \multicolumn{3}{|c|}{ Planting to $\mathrm{R3}^{\mathrm{z}}$} & \multicolumn{3}{|c|}{$\mathrm{R3}^{\mathrm{z}}$ to harvest } \\
\hline & \multicolumn{2}{|c|}{$\begin{array}{c}\text { Temperature } \\
\left({ }^{\circ} \mathbf{C}\right)\end{array}$} & \multirow{2}{*}{$\begin{array}{c}\begin{array}{c}\text { Rainfall } \\
(\mathrm{mm})\end{array} \\
\text { Total }\end{array}$} & \multicolumn{2}{|c|}{$\begin{array}{c}\text { Temperature } \\
\left({ }^{\circ} \mathrm{C}\right)\end{array}$} & \multirow{2}{*}{$\begin{array}{c}\begin{array}{c}\text { Rainfall } \\
(\mathbf{m m})\end{array} \\
\text { Total }\end{array}$} \\
\hline & $\overline{\operatorname{Max}}$ & $\overline{\text { Min }}$ & & $\overline{\operatorname{Max}}$ & $\overline{\operatorname{Min}}$ & \\
\hline$\overline{\mathrm{DE}}$ & 28.6 & 18.7 & 495 & 28.9 & 16.7 & 72 \\
\hline MD & 30.2 & 17.8 & 140 & 21.5 & 9.1 & 236 \\
\hline VA & 32.3 & 20.3 & 354 & 27.7 & 17.7 & 201 \\
\hline
\end{tabular}

y Planting, treatment, and harvest dates are in Table 1.

${ }^{\mathrm{z}}$ Treatments were applied at the milk (R3) stage of the corn crop. infection across experiments, there were no treatment by experiment interactions $(P>0.05)$. Across all three experiments, ears infested with $H$. halys or inoculated with Fusarium had higher frequencies of Fusarium infection compared with nontreated ears (Table 4).

Infection severity based on quantified $F$. verticillioides DNA in the kernels differed among $H$. halys treatment $(P=0.022)$, Fusarium treatment $(P<0.0001)$, and experiment $(P<0.0001)$, and there was a significant $H$. halys by Fusarium interaction $(P=0.0018)$. However, treatment effects were similar across locations (treatment by experiment interactions, $P>0.05)$. $F$. verticillioides DNA concentration was highest in the VA samples (mean $=9.8 \mathrm{ng} F$. verticillioides DNA/g corn), whereas DE and MD samples had concentrations 0.03 and $0.002 \mathrm{ng} / \mathrm{g}$, respectively. The highest levels of infection were detected in ears that were both infested with $H$. halys and inoculated with $F$. verticillioides; levels of infection were similar among untreated ears and those with either a $H$. halys or Fusarium treatment alone (Fig. 1).

Fumonisin concentrations in harvested grain varied among locations $(P=0.035)$. For the DE experiment, the $22 \%$ of samples with detectable fumonisin ranged from 0.3 to $34 \mathrm{ppm}($ mean $=8 \mathrm{ppm})$, with an overall mean of $0.54 \mathrm{ppm}$ for all samples. For the VA experiment, $25 \%$ of samples with detectable fumonisin ranged from 0.4 to $17 \mathrm{ppm}$ (mean $=4.1 \mathrm{ppm}$ ) with an overall mean of $0.50 \mathrm{ppm}$ for all samples. The MD experiment had the lowest frequency and concentration of detectable fumonisin with $4 \%$ of samples with detectable fumonisin ranging from 3 to $12 \mathrm{ppm}($ mean $=7.5)$ with an overall mean of $1.1 \mathrm{ppm}$. There was an interaction between $H$. halys and Fusarium treatments $(P=0.036)$ and fumonisin concentrations were highest when both $H$. halys and Fusarium treatments were applied (Fig. 1). H. halys or Fusarium treatment alone did not increase fumonisin concentrations in the grain.

\section{Discussion}

In this study, the relationship between $H$. halys, Fusarium infection, and mycotoxin contamination was characterized, and an interaction between $H$. halys feeding and fumonisin contamination was identified. This suggests that invasive $H$. halys not only directly injures the crop through feeding but may also indirectly increase the impacts of mycotoxigenic fungi. This relationship thereby increases $H$. halys damage potential in field corn, and this may have implications for corn pest management in the mid-Atlantic as invasive $H$. halys spreads throughout corn production areas.

$H$. halys can cause significant economic damage in orchard crops (e.g., apples, peaches) and fresh vegetables (e.g., tomato, pepper, sweet corn) where direct damage to the marketable portion of the crop reduces quality and marketable yield (Kuhar et al. 2012; Leskey et al. 2012a; Rice et al. 2014). In field corn, other native species of stink bugs can cause feeding injury but typically do not cause economic damage (Clower 1958; Ni et al. 2010). In contrast, the higher population densities of $H$. halys found in field corn and other crops

Table 4. Main effects of Halyomorpha halys infestation, Fusarium verticillioides inoculation, and experiment on frequencies of stink bug feeding injury and Fusarium infection in corn

\begin{tabular}{lccc}
\hline Treatment factor & Level & $\begin{array}{c}\text { Feeding } \\
\text { injury, } \mathbf{\%} \mathbf{x}, \mathbf{y}\end{array}$ & $\begin{array}{c}\text { Fusarium } \\
\text { infection, } \mathbf{\%}, \mathbf{z}\end{array}$ \\
\hline H. halys & Yes & $4.7 \mathrm{a}$ & $32.1 \mathrm{a}$ \\
F. verticillioides & No & $1.7 \mathrm{~b}$ & $23.8 \mathrm{~b}$ \\
Experiment (location) & Yes & $3.1 \mathrm{a}$ & $32.2 \mathrm{a}$ \\
& No & $3.0 \mathrm{a}$ & $23.7 \mathrm{~b}$ \\
& DE & $2.4 \mathrm{~b}$ & $30.8 \mathrm{~b}$ \\
& MD & $2.1 \mathrm{~b}$ & $11.7 \mathrm{c}$ \\
& VA & $5.0 \mathrm{a}$ & $44.5 \mathrm{a}$ \\
\hline
\end{tabular}

x Percentage data were arcsine transformed prior to analysis of variance, and detransformed means are presented. Means followed by different letters are significantly different according to Tukey's HSD.

${ }^{y}$ Percent of harvested kernels with signs of stink bug feeding injury.

${ }^{\mathrm{z}}$ Percent of harvested kernels infected with Fusarium based on plating $20 \mathrm{ker}-$ nels per corn ear sample on 1/4 strength potato dextrose agar. 
result in a greater potential for economic damage. $H$. halys feed primarily on field edges (Venugopal et al. 2014), which localizes damage, but application of effective chemical controls is difficult in field corn that has passed the tasseling stage (Rice et al. 2014). Indeed, the poorly understood economic importance and lack of management strategies for $H$. halys in field corn have hindered the development of an economic threshold.

This study identifies and quantifies potential economic impacts of $H$. halys resulting from mycotoxin contamination. Both the field survey and the field experiment demonstrated the ability of $H$. halys to increase Fusarium infection and fumonisin contamination. In the field survey, the observation of increased $H$. halys population numbers and associated injury occurring at the edge of corn fields compared with the middle is consistent with other studies focused on apple, peach, soybean, and ornamentals (Leskey et al. 2012a). Therefore, comparing samples collected from the edge and the middle (12 to 20 rows from the edge) was a useful approach to characterizing the impact of $H$. halys within the same surveyed field. A shortcoming of the field survey was that it was not possible to distinguish between kernel feeding injury caused by $H$. halys and that of native stink bugs and other insects. However, high numbers of $H$. halys were observed during the growing season in the sampled fields, and the injury assessed on the kernels resembled previous descriptions of $H$. halys feeding. Also, since $H$. halys infestation was greatest at the edges compared with interior portions of fields, "edge effect" factors may have contributed to increased levels of fungal infection and mycotoxin contamination. Plants grown at the edges of agriculture fields often experience harsh treatments such as excess chemical deposit, drought, and poor soil nutrient leading to poor plant health and stress. Poor plant health and stress may reduce their capacity to resist pathogen invasion and subsequent mycotoxin contamination (Miller 2001). Again, the survey was conducted at multiple locations with variable levels of $H$. halys infestation and different environmental conditions leading to variable amount of damage, fungal infections, and mycotoxin contamination. Nevertheless, the pattern of high damage, high infection, and high fumonisin concentrations was associated with $H$. halys infestation across all locations.

In the experiment conducted to assess the impacts of $H$. halys on $F$. verticillioides infection and fumonisin concentrations, relatively low levels of $H$. halys feeding injury, Fusarium infection, and fumonisin concentrations were detected compared with the field survey. This may have been influenced by environmental conditions at the time of the experiments. However, a lack of treatment by experimental location interactions indicates treatment effects were similar across experiments. Although injury was low, only $H$. halys treatment significantly affected injury measurements, which indicates observed damage was primarily due to $H$. halys feeding and not fungal infection or other insect damage. Environmental conditions in Virginia were favorable for infection and $H$. halys feeding and the Virginia site exhibited relatively high injury, infection, and fumonisin concentrations. The lower injury, incidence and severity of infection, and fumonisin concentrations recorded in Maryland could be attributed to late planting, which caused the experiment to coincide with colder environmental conditions. It is possible that the low temperatures may have reduced $H$. halys feeding and also suppressed the growth and infection of $F$. verticillioides leading to low levels of injury, infection, and subsequent fumonisin concentration. The Delaware site experienced consistently favorable temperatures for $F$. verticillioides infection from treatment application to harvest, but the long period of drought during that time may have limited infection and induced drought stress in the corn. Warm $\left(>27^{\circ} \mathrm{C}\right)$ and droughty conditions favor Fusarium ear rot development and subsequent fumonisin contamination (Miller 2001; Pascale et al. 1997; Shelby et al. 1994), which could explain the relatively high fumonisin concentrations in Delaware samples. Fusarium infection was detected in kernels from noninoculated ears, but this is not unexpected since $F$. verticillioides and other Fusarium spp. are common in the environment and $F$. verticillioides can survive as an endophyte without resulting in any symptoms (Bacon and Hinton 1996; Leslie and Summerell 2006; Yates et al. 1997). However, systemic infections appear to contribute little to ear mold symptoms and fumonisin concentrations (Desjardins et al. 2002; Munkvold et al. 1997).

Even though this experiment demonstrates the ability of $H$. halys to increase $F$. verticillioides infection and fumonisin concentrations, it does not demonstrate possible mechanisms responsible for these effects. Possibly, the feeding damage served as a channel for invasion as demonstrated in other studies (Avantaggiato et al. 2002; Munkvold 2003; Payne 1999; Smeltzer 1959; Yates and Sparks 2008). Also, kernel infection through the inoculation of silk with spore suspension is possible (Munkvold et al. 1997; Reid et al. 1992) and that may in part explain why some ears without observable damage had high frequency of infection. Thus, it is possible that $H$. halys feeding injury is what facilitated infection and the resultant fumonisin contamination, and it is also likely that silk infection prior to treatment application may have contributed to the observed kernel infection.

Another possible mechanism for the increased infection could be that $H$. halys may be vectoring Fusarium spp. either externally or internally, thereby increasing the quantity of inoculum present during the time of feeding and facilitating infection and mycotoxin contamination. The vectoring capacity of $H$. halys has been reported in other studies. $H$. halys was found to be a vector for the phytoplasma that
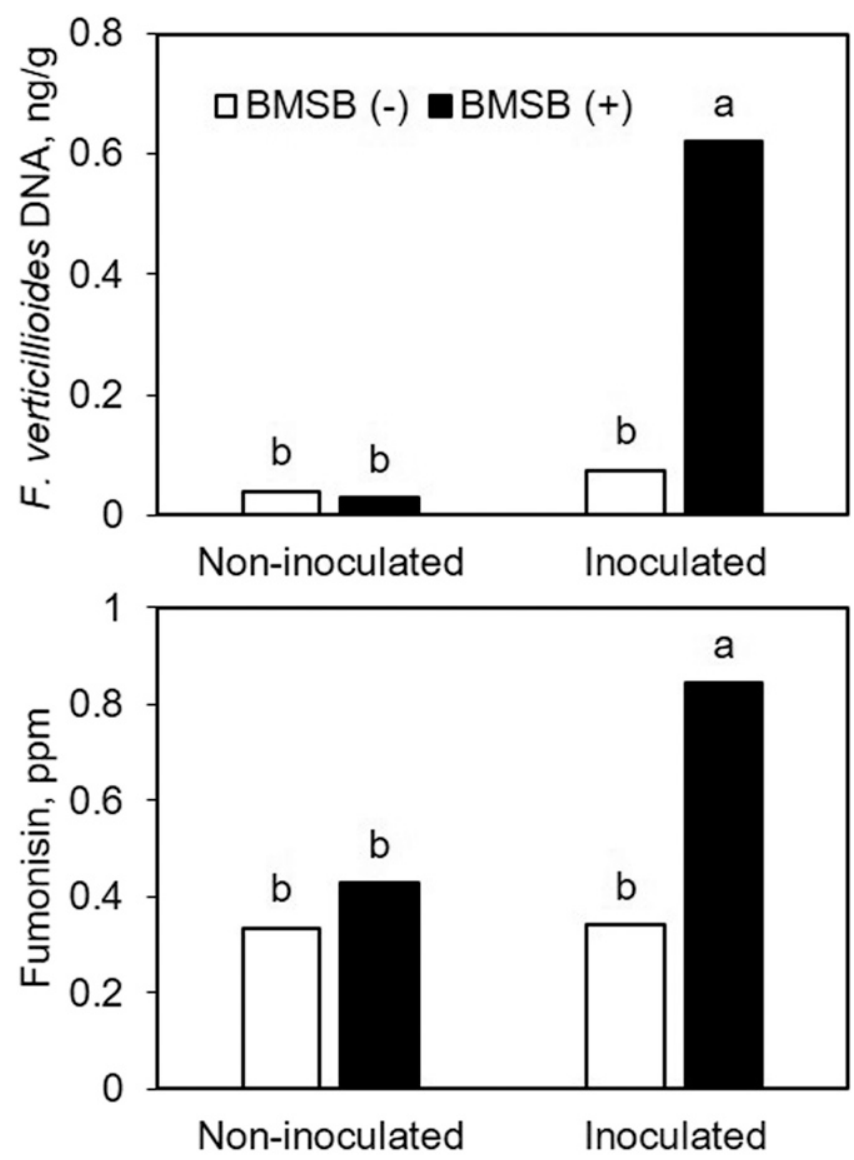

Fusarium inoculation

Fig. 1. Impact of brown marmorated stink bug (BMSB) (Halyomorpha halys) and Fusarium verticillioides treatments on fungal infection severity (top) and fumonisin concentrations (bottom) in corn kernels. $H$. halys (with or without four adult $H$. halys) and $F$. verticillioides (with or without inoculation) treatments were applied to corn ears at the milk (R3) stage of kernel development in a factorial design. Following harvest, fungal infection was quantified by real-time PCR using $F$. verticillioides-specific primers, and fumonisin concentrations were determined using a Neogen Reveal Q+ kit. Data were log transformed prior to an analysis of variance, and there was a significant $H$. halys by $F$. verticillioides treatment interaction for both infection $(P=0.0018)$ and fumonisin $(P=0.0360)$. Means were compared using Tukey's HSD, and detransformed means are presented. Bars with different letters are significantly different from each other according to Tukey's HSD. 
causes witches'-broom in the princess tree (Paulownia tomentosa) in Japan, Korea, and China (Bak et al. 1993: Hiruki 1999; Weintraub and Beanland 2006). The capacity of $H$. halys to phoretically carry infective Colletotrichum spores from diseased tomatoes to healthy ones has been demonstrated (Voshell et al. 2015).

Only fumonisin was associated with $H$. halys in this study, and other studies have reported a significant correlation between extent of insect damage and fumonisin levels in field corn (Dowd 2001; Munkvold et al. 1999). However, it is possible that environmental conditions during the growing season may have contributed to this association rather than the inability of $H$. halys to increase deoxynivalenol or aflatoxin contamination in corn. For example, $A$. flavus infection and associated aflatoxin contamination, which are favored by hot, dry, and drought conditions (Diener et al. 1987; Klich 1987), are less common in the mid-Atlantic but can be a significant problem in seasons with favorable weather conditions. Also, F. verticillioides sporulates greatly under humid and warm conditions of about $27^{\circ} \mathrm{C}$ (Rossi et al. 2009), which corresponds to typical environmental conditions in the mid-Atlantic during the summer months when corn is grown. Other studies have also shown that corn kernels colonized by $F$. verticillioides are less likely to be significantly colonized by other mycotoxin producers such as $F$. graminearum, $F$. subglutinans, and Aspergillus spp. (Marín et al. 1998a, b; Rheeder et al. 1990); hence, $F$. verticillioides infection would have the greatest frequency if it was first to colonize the ear.

$H$. halys is invasive and is likely to spread throughout the U.S. within a few years (Holtz and Kamminga 2010; Zhu et al. 2012); hence, it will continue to be a potential economic threat to a wide range of agricultural production systems in the United States. It is also a risk factor for fumonisin and perhaps other mycotoxin contamination in field corn, and mycotoxin concentrations may increase as a result of $H$. halys population increases and spread across the landscape. Risk of mycotoxin contamination associated with $H$. halys can be mitigated by better characterizing the relationship between $H$. halys and mycotoxin-producing Fusarium spp., including testing the ability of $H$. halys to vector Fusarium spp., quantifying overall impact of $H$. halys infestations on mycotoxin contamination especially at the edges of the field where their populations are frequently high. It may also be important to monitor mycotoxin contamination events over multiple sites and states where $H$. halys occurs and correlate that with insect and fungal control practiced by growers to determine best practices that ameliorates their impacts. During high $H$. halys infestation, it may be precautious for growers to practice selective harvest ( $\mathrm{Ni}$ et al. 2011). Thus, growers should harvest the middle parts of their fields separate from the edges of their fields and assess both harvests separately for damage and mycotoxin contamination and only mix them when necessary. Although the Cry $1 \mathrm{Ab}$ protein in Bt corn dramatically reduced corn-borer damage leading to less Fusarium infection and fumonisin contamination (Betz et al. 2000; Hammond et al. 2004), H. halys is able to cause substantial damage, which may be a precursor for high Fusarium infection and fumonisin contamination. Therefore, the search for new natural fungal and insect resistance mechanisms and developing hybrids that are resistant to insect damage and fungal infection or produce enzymes that degrade fumonisin as it is produced would reduce mycotoxin incidence appreciably (Abbas et al. 2013; Cleveland et al. 2003). Also, because the $H$. halys adults are mobile and move in large numbers, they attack large numbers of plants at a time and cause extensive damage. Quarantine agencies and other players in the agriculture sector must be interested in the infestation dynamics of $H$. halys so that commodities coming from areas with high $H$. halys infestation would be critically scrutinized for mycotoxins since apart from feeding damage reducing quality, such commodities may have an additional risk of mycotoxin contamination.

In conclusion, the results suggest $H$. halys has the ability to increase both Fusarium infection and fumonisin concentrations in field corn. However, further studies are needed to understand mechanisms by which $H$. halys increases fumonisin, and possibly other mycotoxins. Studies about $H$. halys transmitting mycotoxin-producing fungi during feeding and how that contributes to the total mycotoxin contamination should be conducted. Also, further studies have to be carried out to understand the population dynamics of $H$. halys and set population threshold in field corn that would serve as a critical control point. Additional studies should be carried out to estimate how much selective harvest would contribute to a reduced impact of mycotoxin contamination in $H$. halys-infested corn fields. Understanding of the mechanisms involved in the increased mycotoxin contamination in field corn would help in the formulation of management strategies to mitigate impacts of $H$. halys on field corn in the region.

\section{Acknowledgments}

We would like to thank Ed Seymore and Jamie Hogue, the scouts of the annual statewide Virginia Soybean Insect Pest Surveillance Program, for help with the scouting, collection of samples, and for identification of $H$. halys-damaged corn kernels for the field survey. For support and assistance in conducting the study in Maryland, we thank Kevin Conover, Terry Patton, Margaret Lewis, and

Dr. Galen Dively. Our deepest appreciation also goes to the technicians including Linda Byrd-Masters, Richard (Steve) Byrum, and Ed Hobbs, and student interns Cris Ramage and Matilda Meding, who assisted in executing various aspects of laboratory and field activities.

\section{Literature Cited}

Abbas, H. K., Zablotowicz, R. M., Weaver, M. A., Shier, W. T., Bruns, H. A., Bellaloui, N., Accinelli, A., and Abel, C. A. 2013. Implications of $\mathrm{Bt}$ traits on mycotoxin contamination in maize: Overview and recent experimental results in southern United States. J. Agric. Food Chem. 61:11759-11770.

Avantaggiato, G., Quaranta, F., Desiderio, E., and Visconti, A. 2002. Fumonisin contamination of maize hybrids visibly damaged by Sesamia. J. Sci. Food Agric. 83:3-8.

Bacon, C. W., and Hinton, D. M. 1996. Symptomless endophytic colonization of maize by Fusarium moniliforme. Can. J. Bot. 74:1195-1202.

Bak, W. C., Yeo, W. H., and La, Y. J. 1993. Little-leaf symptom development in the periwinkle infected with paulownia witches'-broom mycoplasma-like organism by the yellow-brown stink bug, Halyomorpha halys Stål (H. mista Uhler). Korean J. Plant Pathol. 9:236-238.

Barnett, H. L., and Hunter, B. B. 1998. Illustrated genera of imperfect fungi, 4th ed. APS Press, St. Paul, MN.

Betz, F. S., Hammond, B. G., and Fuchs, R. L. 2000. Safety and advantages of Bacillus thuringiensis - protected plants to control insect pests. Regul. Toxicol. Pharmacol. 32:156-173.

Cissel, W. J., Mason, C. E., Whalen, J., Hough-Goldstein, J., and Hooks, C. R. R. 2015. Effects of brown marmorated stink bug (Hemiptera: Pentatomidae) feeding injury on sweet corn yield and quality. J. Econ. Entomol. 108: 1065-1071.

Cleveland, T. E., Dowd, P. F., Desjardins, A. E., Bhatnagar, D., and Cotty, P. J. 2003. United States Department of Agriculture-Agricultural Research Service research on pre-harvest prevention of mycotoxins and mycotoxigenic fungi in US crops. Pest Manag. Sci. 59:629-642.

Clower, D. F. 1958. Damage to corn by the southern green stink bug. J. Econ. Entomol. 51:471-473.

Desjardins, A. E., Munkvold, G. P., Plattner, R. D., and Proctor, R. H. 2002 FUM1-a gene required for fumonisin biosynthesis but not for ear rot and ear infection by Gibberella moniliformis in field tests. Mol. Plant-Microbe Interact. 15:1157-1164.

Diener, U. L., Cole, R. J., Sanders, T. H., Payne, G. A., Lee, L. S., and Klich, M. A 1987. Epidemiology of aflatoxin formation by Aspergillus flavus. Annu. Rev. Phytopathol. 25:249-270.

Dowd, P. F. 1998. Involvement of arthropods in the establishment of mycotoxigenic fungi under field conditions. Pages 307-350 in: Mycotoxins in agriculture and food safety. K. K. Sinha and D. Bhatnagar, eds. Marcel Dekker, New York.

Dowd, P. F. 2001. Biotic and abiotic factors limiting efficacy of Bt corn in indirectly reducing mycotoxin levels in commercial fields. J. Econ. Entomol. 94:1067-1074.

El-Nezami, H., Polychronaki, N., Salminen, S., and Mykkanen, H. 2002. Binding rather than metabolism may explain the interaction of two food-grade Lactobacillus strains with zearalenone and its derivative $\alpha$-zearalenol. Appl. Environ. Microbiol. 68:3545-3549.

Hamilton, G. C. 2009. Brown marmorated stink bug. Am. Entomol. (Lanham Md.) $55: 19-20$.

Hamilton, G. C., and Shearer, P. W. 2003. Brown marmorated stink bug-a new exotic insect in New Jersey. FS002. Rutgers University Cooperative Extension, New Brunswick, NJ.

Hammond, B. G., Campbell, K. W., Pilcher, C. D., Degooyer, T. A., Robinson, A. E., Mcmillen, B. L., Spangler, S. M., Riordan, S. G., Rice, L. G., and Richard, J. L. 2004. Lower fumonisin mycotoxin levels in the grain of Bt corn grown in the United States in 2000-2002. J. Agric. Food Chem. 52 $1390-1397$. 
Hedstrom, C., Shearer, P., Miller, J., and Walton, V. 2014. The effects of kernel feeding by Halyomorpha halys (Hemiptera: Pentatomidae) on commercial hazelnuts. J. Econ. Entomol. 107:1858-1865.

Hiruki, C. 1999. Paulownia witches'-broom disease important in East Asia. Acta Hortic. 496:63-68.

Hoebeke, E. R., and Carter, M. E. 2003. Halyomorpha halys (Stål) (Heteroptera: Pentatomidae): a polyphagous plant pest from Asia newly detected in North America. Proc. Entomol. Soc. Wash. 105:225-237.

Holtz, T., and Kamminga, K. 2010. Qualitative analysis of the pest risk potential of the brown marmorated stink bug (BMSB), Halyomorpha halys (Stål), in the United States. Plant Epidemiology and Risk Analysis Laboratory of the Center for Plant Health Science and Technology (USDA-APHIS). https:// www.michigan.gov/documents/mda/BMSB_Pest_Risk_Potential_-_USDA_ APHIS Nov_2011_344862 7.pdf

Klich, M. A. 1987. Relation of plant water potential at flowering to subsequent cottonseed infection by Aspergillus flavus. Phytopathology 77:739-741.

Kuhar, T. P., Kamminga, K. L., Whalen, J., Dively, G. P., Brust, G., Hooks, C. R. R., Hamilton, G., and Herbert, D. A. 2012. The pest potential of brown marmorated stink bug on vegetable crops. Plant Health Prog.

Kurtz, H. J., and Mirocha, J. 1978. Zearalenone (F2) induced estrogenic syndrome in swine. Pages 1256-1264 in: Mycotoxic fungi, mycotoxins, mycotoxicoses. T. D. Wyllie and L. G. Morehouse, eds. Marcel Dekker, New York.

Lee, D. H. 2015. Current status of research progress on the biology and management of Halyomorpha halys (Hemiptera: Pentatomidae) as an invasive species. Appl. Entomol. Zool. (Jpn.) 50:277-290.

Leskey, T. C., Hamilton, G. C., Nielsen, A. L., Polk, D. F., Rodriquez-Saona, C., Christopher, B., Herbert, D. A., Kuhar, T. P., Pfeifer, D., Dively, G. P., Hooks, C., Raupp, M. J., Shrewsbury, P. M., Krawczyk, G., Shearer, P. W., Whalen, J., Koplinka-Loeher, C., Myers, E., Inkley, D., Hoelmer, K. A., Lee, D. H., and Wright, S. E. 2012a. Pest status of the brown marmorated stink bug (Halyomorpha halys) in the USA. Outlooks Pest Manag. 23:218-226.

Leskey, T. C., Short, B. D., Butler, B. R., and Wright, S. E. 2012b. Impact of the invasive brown marmorated stink bug, Halyomorpha halys (Stål), in midAtlantic tree fruit orchards in the United States: Case studies of commercial management. Psyche (Stuttg.) 2012:535062.

Leslie, J. F., and Summerell, B. A., eds. 2006. The Fusarium laboratory manual. Blackwell Publishing, Ames, IA.

Marín, S., Sanchis, V., Arnau, F., Ramos, A. J., and Magan, N. 1998a. Colonisation and competitiveness of Aspergillus and Penicillium species on maize grain in the presence of Fusarium moniliforme and Fusarium proliferatum. Int. J. Food Microbiol. 45:107-117.

Marín, S., Sanchis, V., Ramos, A. J., Vinas, I., and Magan, N. 1998b. Environmental factors, in vitro interactions, and niche overlap between Fusarium moniliforme, $F$. proliferatum and F. graminearum, Aspergillus and Penicillium species from maize grain. Mycol. Res. 102:831-837.

Miller, J. D. 2001. Factors that affect the occurrence of fumonisin. Environ. Health Perspect. 109:321-324

Mitchell, N. J., Bowers, E., Hurburgh, C., and Wu, F. 2016. Potential economic losses to the USA corn industry from aflatoxin contamination. Food Addit. Contam. Part A 33:540-550.

Mulè, G., Susca, A., Stea, G., and Moretti, A. 2004. Specific detection of the toxigenic species Fusarium proliferatum and $F$. oxysporum from asparagus plants using primers based on calmodulin gene sequences. FEMS Microbiol. Lett. 230:235-240.

Munkvold, G., Hellmich, R., and Rice, L. 1999. Comparison of fumonisin concentrations in kernels of transgenic Bt maize hybrids and nontransgenic hybrids. Plant Dis. 83:130-138.

Munkvold, G. P. 2003. Epidemiology of Fusarium diseases and their mycotoxins in maize ears. Eur. J. Plant Pathol. 109:705-713.

Munkvold, G. P., McGee, D. C., and Carlton, W. M. 1997. Importance of different pathways for maize kernel infection by Fusarium moniliforme. Phytopathology 87:209-217.

Ni, X., Da, K., Buntin, G., Cottrell, T. E., Tillman, P. G., Olson, D. M., Powell, R., Lee, R. D., Wilson, J. P., and Scully, B. T. 2010. Impact of brown stink bug (Heteroptera: pentatomidae) feeding on corn grain yield components and quality. J. Econ. Entomol. 103:2072-2079.

Ni, X., Wilson, J. P., Buntin, G. D., Guo, B., Krakowsky, M. D., Lee, R. D., Cottrell, T. E., Scully, B. T., Huffaker, A., and Schmelz, E. A. 2011. Spatial patterns of aflatoxin levels in relation to ear- feeding insect damage in preharvest corn. Toxins (Basel) 3:920-931.

Nielsen, A. L., and Hamilton, G. C. 2009. Seasonal occurrence and impact of Halyomorpha halys (Hemiptera: Pentatomidae) in tree fruit. J. Econ. Entomol. 102:1133-1140.

O’Donnell, K., Kistler, H. C., Cigelnik, E., and Ploetz, R. C. 1998. Multiple evolutionary origins of the fungus causing Panama disease of banana: Concordant evidence from nuclear and mitochondrial gene genealogies. Proc. Natl. Acad. Sci. USA 95:2044-2049.

Pascale, M. A., Visconti, A., Pronczuk, M., Wisniewska, H., and Chelkowski, J. 1997. Accumulation of fumonisins in maize hybrids inoculated under field conditions with Fusarium moniliforme Sheldon. J. Sci. Food Agric. 74:1-6.

Payne, G. A. 1999. Ear and kernel rots. Pages 44-47 in: Compendium of Corn Diseases, 3rd ed. D. G. White, ed. APS Press, St Paul, MN.

Reid, L. M., Bolton, A. T., Hamilton, R. I., Woldemariam, T., and Mather, D. E. 1992. Effect of silk age on resistance of maize to Fusarium graminearum. Can. J. Plant Pathol. 14:293-298.

Rheeder, J. P., Marasas, W. F. O., and Van Wyk, P. S. 1990. Fungal associations in corn kernels and effects on germination. Phytopathology 80:131-134.

Rice, K. B., Bergh, J., Bergmann, E. J., Biddinger, D. J., Dieckhoff, C., Dively, G., Fraser, H., Gariepy, T., Hamilton, G., Haye, T., Herbert, A., Hoelmer, K., Hooks, C. R., Jones, A., Krawczyk, G., Kuhar, T., Martinson, H., Mitchell, W., Nielsen, A. L., Pfeiffer, D. G., Raupp, M. J., Rodriquez-Saona, C., Shearer, P., Shrewsbury, P., Venugopal, P. D., Whalen, J., Wilman, N. G., Leskey, T., and Tooker, J. F. 2014. Biology, ecology, and management of brown marmorated stink bug (Hemiptera: Pentatomidae). J. Integr. Pest Manag. 5:A1-A13.

Rossi, V., Scandolara, A., and Battilani, P. 2009. Effect of environmental conditions on spore production by Fusarium verticillioides, the causal agent of maize ear rot. Eur. J. Plant Pathol. 123:159-169.

Shelby, R. A., White, D. G., and Bauske, E. M. 1994. Differential fumonisin production in maize hybrids. Plant Dis. 78:582-584.

Smeltzer, D. G. 1959. Relationship between Fusarium ear rot and corn earworm infestation. Agron. J. 51:53-54.

Stumpf, R., dos Santos, J., Gomes, L. B., Silva, C. N., Tessmann, D. J., Ferreira, F. D., Machinski, J. M., and Del Ponte, E. M. 2013. Fusarium species and fumonisins associated with maize kernels produced in Rio Grande do Sul State for the 2008/09 and 2009/10 growing seasons. Braz. J. Microbiol. 44 89-95.

Taylor, C. M., Coffey, P. L., Hamby, K. A., and Dively, G. P. 2017. Laboratory rearing of Halyomorpha halys: methods to optimize survival and fitness of adults during and after diapause. J. Pest Sci. 90:1069-1077.

Vardon, P. J., McLaughlin, C., and Nardinelli, C. 2003. Potential economic costs of mycotoxins in the United States. Council of Agricultural Science and Technology (CAST) Mycotoxins: Risks in plant, animal and human systems. Task Force Report No. 139. CAST, Ames, IA

Venugopal, P. D., Coffey, P. L., Dively, G. P., and Lamp, W. O. 2014 Adjacent habitat influence on stink bug (Hemiptera: Pentatomidae) densities and the associated damage at field corn and soybean edges. PLoS One 9:e109917

Venugopal, P. D., Galen, P., Dively, G. P., and Lamp, W. O. 2015. Spatiotemporal dynamics of the invasive Halyomorpha halys (Hemiptera: Pentatomidae) in and between adjacent corn and soybean fields. J. Econ. Entomol. 108:2231-2241.

Voshell, R. J., Yong-Lak, P., Rahman, M., Panaccione, D., and Kotcon, J. 2015 Interactions of brown marmorated stink bug, Colletotrichum acutatum and trap crops in organic tomato production. Thesis. West Virginia University, Morgantown, WV

Weintraub, P. G., and Beanland, L. 2006. Insect vectors of phytoplasmas. Annu. Rev. Entomol. 51:91-111.

Yates, I. E., Bacon, C. W., and Hinton, D. M. 1997. Effects of endophytic infection by Fusarium moniliforme on corn growth and cellular morphology. Plant Dis. 81:723-728.

Yates, I. E., and Sparks, D. 2008. Fusarium verticillioides dissemination among maize ears of field-grown plants. Crop Prot. 27:606-613.

Zhu, G., Bu, W., Gao, Y., and Liu, G. 2012. Potential geographic distribution of brown marmorated stink bug invasion (Halyomorpha halys). PLoS One 7: e31246. 